\title{
The Testing Method of the Co-Movement of A+H Stock Prices
}

\author{
Jing Xiang, Susheng Wang \& Jiaji Hao \\ Department of Economics and Management \\ Harbin Institute of Technology Shenzhen Graduate School, Shenzhen 518055, China \\ E-mail: carol.hsiang@163.com
}

\begin{abstract}
In this paper, the technical methods utilized for testing the co-movement of $\mathrm{A}+\mathrm{H}$ stock prices of dual listed companies were analyzed through co-integration test, the Granger causality test, variance decomposition and Geweke indicators. Currently, empirical research on $\mathrm{A}+\mathrm{H}$ stock markets are mainly based on two perspectives: empirical analysis of international asset price equalization theory and empirical analysis of measurement technology. Commonly there are four base unit test methods: Dickey-Fuller test, Augmented Dickey-Fuller test, Phillips and Perron test and KPSS test. These indicators and methods are then analyzed and evaluated. Research has not yet found an ideal approach to link $\mathrm{A}+\mathrm{H}$ stock markets, although the above mentioned methods complement each other. In short, these test theories for development are only used in practice. With expanding research, in the future, there will be more powerful theoretical tools for empirical analysis.
\end{abstract}

Keywords: The dual listed companies stock, Co-movement, Testing method

\section{INTRODUCTION}

Co-movement refers to a strong correlation among yields of different markets, or that different stock prices share a common long-run equilibrium relationship or possess a long-term trend of synchronized movement. With communication technology and data processing technology improvement, finance theory and technology development, and development of derivatives market, the world capital market is deregulating, as well as the rapid expansion of institutional investors for spreading the risks. These forces will inevitably promote the linkage of $\mathrm{A}+\mathrm{H}$ stock markets.

Research on the linkage of the trends of dual-listed stocks, on the micro level, will help vast numbers of investors in securities to perform portfolio analysis, and forecast prices to spread risks and raise revenue. At the same time, will also help listed companies specify financing strategy, and realize capital internationalization. From a macro perspective, a linkage of the stock reflects the overall linkage of the stock markets. It is valuable for regulatory authorities to enhance policy and better safeguard against financial risks. Many of the financial forecasts are based on the long-run equilibrium and short-term dynamic relationship. Inspection of the direction and the strength of the trend will help establish future profit strategy. If no co-integration exists, it means that diversified investment in these markets will be accessible for long-term hedging. If there is co-integration relationship, we can create short-term profit models.

\section{MAIN INDICATORS FOR TESTING THE CO-MOVEMENT}

Currently, empirical research on $\mathrm{A}+\mathrm{H}$ stock markets are mainly based on two perspectives; empirical analysis of international asset price equalization theory and empirical analysis on measurement technology. The former analyzes whether the same risk securities have the same prices or not. If the test is passed, this shows that the linkage effects of markets are so high that the realization of asset price movements is in absolute synchronization. According to different research methods, the model is subdivided into the international capital asset pricing model and international arbitrage pricing model. In fact, the research literature can be found in Stehle (1977) fixed proceeds CAPM, Errunza and Losq (1985) moderate market segmentation theory, Cho, Eun and Senbet (1986) of fixed-income IAPT, Bekaert and Harvey (1995) time-varying expected return IntCAPM and so on. The conclusions of these models are not the same because their conditions and forms are different. International asset price equalization theory is impeccable from a purely theoretical point of view, but in empirical testing, inevitably encounters problems on the asset pricing model and linkage testing among $\mathrm{A}+\mathrm{H}$ stock markets. Therefore, the usefulness of the theory for testing the market linkage is a greatly reduced. However, the rapid development of measurement technology makes up for the shortcomings of securities market linkage measure tools.

Some scholars try to bypass the asset pricing model, from a practical point of view of technical indicators, to inspect the linkage of the securities markets, and bring out the relevant parameters, co-integration, Granger causality, such as a series of theoretical methods and their expansion. 


\section{CO-INTEGRATION THEORY}

Before introducing the co-integration theory, we first introduce several important basic concepts. a) Stationary time series, set $Y$ is time series, and if $E(Y)=\lambda$ and $\operatorname{Var}(Y)=\delta_{y}{ }^{2}, Y$ is a stationary time series, that is $I(0)$. For stationary series, its mean and variance are unchanged, even by the temporary impact of external factors. But in the long term, it will return to its average level. b) Non-stationary time series: variance sequence does not return to the average level of convergence and the variance unlimited increases. c) Single co-integration: If a non-stationary time series experience $k$ times difference, it constitutes a stationary time series, then called it $k$ single-band, that is $I(k)$.

At present, co-integration test has become a major method to test linkage of $\mathrm{A}+\mathrm{H}$ stock markets.

\section{A. Unit Root Test}

Before the statistical analysis of time sequence, we must first determine series integration level using the unit root test, to determine whether the time series is smooth, and avoid the emergence of pseudo-regression. Normally, there are four unit root test methods: Dickey-Fuller (DF) test, Augmented Dickey-Fuller (ADF) test, Phillips and Perron (PP) test and KPSS test.

1)Dickey-Fuller(DF)Test:

Standard DF test is hypothesis testing the following relationship:

$$
\Delta \mathrm{y}_{\mathrm{t}}=\alpha \mathrm{y}_{\mathrm{t}-1}+\mathrm{x}_{\mathrm{t}}^{\prime} \delta+\varepsilon_{\mathrm{\tau}}
$$

The replacement of the original assumption:

$$
\mathrm{H}_{0}: \alpha=0 \quad \mathrm{H}_{1}: \alpha<0
$$

Use traditional statistics $t$ to test $\alpha: t_{\alpha}=\hat{\alpha} /(\operatorname{se}(\hat{\alpha}))$

The above is a simple unit root test and this method is only effective when the sequence is $A R(1)$. If the data sets have a correlation in a higher time lag, then hypothesis that residual value is a white noise has not been established.

\section{2)Augmented Dickey-Fuller (ADF)Test}

Dickey and Fuller (1979) proposed the Dickey-Fuller test, which is based on the assumption that regression residuals are white noise, but in reality the regression residuals may have a serial correlation. In order to resolve this problem, Said and Dickey supposed an Augmented Dickey-Fuller Test. There are three test models:

Model 1: Sequence with no intercept and no time trend items:

$$
\Delta z_{t}=\gamma z_{t-1}+\sum_{i=1}^{R} a_{u} \Delta z_{t-i}+\varepsilon_{t}
$$

Model 2: Sequence with intercept but no time trend of items:

$$
\Delta z_{t}=a_{0}+\gamma z_{t-1}+\sum_{i=1}^{R} a_{u} \Delta z_{t-i}+\varepsilon_{t}
$$

Model 3: sequence with intercept and time trend items:

$$
\Delta z_{t}=a_{0}+a_{1} t+\gamma z_{t-1}+\sum_{i=1}^{R} a_{u} \Delta z_{t-i}+\varepsilon_{t}
$$

Time series data $z_{t}$, and $\varepsilon_{t}$ is the error term. In these three styles it is white noise. $R$ is lag number, and the choice of multi-lag can be selected through different principle (such as: SBC or AIC) to determine $\varepsilon_{t}$ is white noise, $t$ is the trend of the time.

Null hypothesis $H_{0}: \gamma=0$, if refuse null hypothesis, it means that the time series is a smooth sequence, which is $I(0)$; If cannot refuse null hypothesis, it means it is a non-stationary sequence. When a non-stationary time series experience became a smooth sequence after many times difference, this sequence is $I(d)$.

\section{3)Phillips and Perren(PP)Test}

In ADF test, has put time-series variable self-related issues into account. The implied residual seizure model must be non-self relevant and have the same qualitative change. Philips and Perron (1988) proposed non-parameter method based on the function of the central limit theory to amend the DF and ADF, relaxing the basic assumptions that the same qualitative change in the DF test, and developed the PP test, allowing residual items may have relevance and the existence of heterogeneous variability. Its model is: 
$Y_{t}=\mu+\beta(t-T / 2)+\alpha Y_{t-1}+\mu_{t}$

1 test $\alpha=1$ statistic:

$Z\left(t_{\alpha}\right)=\left(s / \sigma_{n}\right) t_{\alpha}-\lambda^{\prime} \sigma_{n} / M^{\frac{1}{2}}$

2 test $\mu=0$ statistic:

$Z\left(t_{u}\right)=\left(s / \sigma_{n}\right) t_{\alpha}-\lambda^{\prime} \sigma_{n} m_{y} / M^{\frac{1}{2}}\left(M+m_{y}^{2}\right)^{\frac{1}{2}}$

3 test $\beta=0$ statistic:

$$
Z\left(t_{\beta}\right)=\left(s / \sigma_{n}\right)-\lambda^{\prime} \sigma_{n}\left(\frac{1}{2} m_{y}-m_{t y}\right) /(M / 12)^{\frac{1}{2}} m_{y y}^{\frac{1}{2}}
$$

4 At the same time test $\alpha=1, \beta=0$, namely test $t_{\mu}=0$. Statistics:

$$
Z\left(t_{\mu}\right)=\left(s / \sigma_{n}\right) t_{\mu}+\lambda^{\prime} \sigma_{n} / \overline{m_{y y}}{ }^{\frac{1}{2}} m_{y y}^{\frac{1}{2}}
$$

5 Does not consider the trend, test $\alpha=1$ statistic:

$$
Z\left(t_{\alpha}\right)=\left(s / \sigma_{n}\right) t_{\alpha}+\lambda^{\prime} \sigma_{n} / m_{y y}^{\frac{1}{2}}
$$

Among them, the sample size $T$ and the standard deviation $s, \lambda=\frac{1}{2}\left(\sigma_{n}^{2}-s_{n}^{2}\right), \lambda^{\prime}=\lambda / \sigma_{n}^{2}$

$$
\begin{aligned}
& m_{y}=T^{-\frac{3}{2}} \sum y_{t} \\
& m_{y y}=T^{-2} \sum y_{t}{ }^{2} \\
& m_{t y}=T^{-\frac{5}{2}} \sum t y_{t} \\
& M=\left(1-T^{-2}\right) m_{y y}-12 m_{y y}{ }^{2}+12\left(1+T^{-1}\right) m_{t y} m_{y} \\
& -\left(4+6 T^{-1}+2 T^{-2}\right) m_{y}^{2}
\end{aligned}
$$

\section{4)KPSS Test}

Since in the ADF test, the null hypothesis is based on the assumption the existence of a single root in the sequence, there must be significant evidence to suggest that there is no single root, then null hypothesis can be refused. The test results tend to think that sequence has a single root; Sims (1988) pointed out that when a smooth sequence is very close to a single process, ADF test power will be lower; Kwiatkowski, Phillips, Schmidt and Shin (1992) supposed a method, which the opposite of zero hypothesis testing methods (referred to KPSS single-root test), the null hypothesis is based on the assumption do not have a single root in the sequence (of the stationary series).

KPSS test formulas have two models:

$z_{t}=r_{t}+\varepsilon_{t} ; r_{t}=r_{t-1}+\mu_{t}$

$z_{t}=\theta t+\gamma_{t}+\varepsilon_{t} ; r_{t}=r_{t-1}+\mu_{t}$

$r_{t}$ is a random item, $u_{t} \sim \operatorname{iid}\left(0, \sigma_{u}^{2}\right)$, from above get the errors $e_{t}, t=1,2,3 \cdots T$, set $s_{t}=\sum_{t=1}^{r} e_{t}, \hat{\sigma}_{\varepsilon}^{2}$ the estimation value of the error variable, the LM statistic is as follows: $L M=\sum_{t=1}^{r} s_{t}^{2} / \hat{\sigma}_{\varepsilon}^{2}$.

The null hypothesis of KPSS test: $H_{0}$ sequence is a smooth sequence. When refuse null hypothesis, it shows that the detection sequence is a smooth sequence.

\section{B. EG Two-Stage Method of Co-integration}

Engle and Granger (1987) supposed two-stage method of co-integration to test whether the two variables are co-integration or not. This method of co-integration test is performing unit root testing the residual of regression equation. On the ideological point of co-integration theory, independent variables and dependent variable have co-integration relationship. 
The first step, using OLS estimation to estimate co-integration regression equation

. $Y_{t}=b_{0}+b_{1} X_{t}+\mu_{t}$

Get residual sequence $e_{t}$, as estimated value of balance error $\mu_{t}$.

The second step, test the stability of $e_{t}$. If $e_{t}$ is a smooth, then $X_{t}$ and $Y_{t}$ are co-integration, and on the other hand, $X_{t}$ and $Y_{t}$ are not co-integration. This is because if $X_{t}$ and $Y_{t}$ are not co-integration, then any linear combination is non-stationary, so residuals $e_{t}$ will be non-smooth. In other words, test whether residual sequence $e_{t}$ is stable, that is, test the existence of co-integration test.

There are some shortcomings of the method in practice, as we only can confirm the existence of co-integration relationship, but we do not know the exact number of co-integration vectors.

\section{GRANGER CAUSALITY TEST}

After doing the unit root test on the non-stationary time series data and examining the co-integration relationships and co-integration vector, which can be clear and accurate understanding of several non-stationary time series data and the long-run equilibrium relationship, and then perform the Granger causality test on the time-series data, to determine whether there are leading and lag relationship in the time series, which is great significance for actual economic and financial analysis and operation. The Granger causality concept was first supposed in 1969 by Granger. Sims (1972) also made a similar definition. Granger causality is based on whether prediction error can be reduced to determine standards, that when the variables $X$ past data will help forecast variables $Y$, namely, that the statistics $Y$ is for the result of $X$, the definition of causal relationship have a more definite conclusion. Following that Granger causality test pattern:

$$
\begin{aligned}
& X_{t}=\alpha_{0}+\sum_{i=1}^{p} \alpha_{i} X_{t-1}+\sum_{i=1}^{p} b_{i} Y_{t-1}+\mu_{1 t} \\
& Y_{t}=\beta_{0}+\sum_{i=1}^{p} c_{i} X_{t-1}+\sum_{i=1}^{p} d_{i} Y_{t-1}+\mu_{2 t}
\end{aligned}
$$

The use of statistical $F$ test, respectively test the above two type of null hypothesis:

$H_{0}: b_{1}=b_{2}=\cdots=b_{p}=0$

$H_{0}^{\prime}: c_{1}=c_{2}=\cdots=c_{p}=0$

Test results, if can not be refused the zero assumption $H_{0}$ and $H_{0}^{\prime}$ at the same time, said that causal relationship does not exist in $X_{t}$ and $Y_{t}$. If refuse zero $H_{0}^{\prime}$ but do not refuse assume $H_{0}$, means that $X_{t}$ leads $Y_{t}$; If refused null hypothesis $H_{0}$ but not rejected $H_{0}^{\prime}$, said $Y_{t}$ leads $X_{t}$; And if refusing two a zero assumption at the same time, means that a feedback causal relationship exists in $X_{t}$ and $\tilde{Y}_{t}$

\section{VARIANCE DECOMPOSITON}

If said that the impulse response function described the effects from the information shock of a new endogenous variable on other variables of VAR model, then variance decomposition will decompose the impact of other variables shocks. We can characterize relative importance (contribution) of each variables impactation. Composed by $k$ variables, VAR model (1) $S$-step prediction error was:

$$
\begin{aligned}
& \operatorname{Var}\left[Y_{t+s}-E\left(Y_{t+s} / Y_{t}, Y_{t-1}, Y_{t-2} \cdots\right)\right] \\
& =\xi_{t+s}+\Psi_{1} \xi_{t+s-1}+\Psi_{2} \xi_{t+s-2}+\cdots+\Psi_{s-1} \xi_{t+1}
\end{aligned}
$$

Its mean-square error was:

$$
\begin{aligned}
& \operatorname{Var}\left[Y_{t+s}-E\left(Y_{t+s} / Y_{t}, Y_{t-1}, Y_{t-2} \cdots\right)\right] \\
& =\xi_{t+s}+\Psi_{1} \xi_{t+s-1}+\Psi_{2} \xi_{t+s-2}+\cdots+\Psi_{s-1} \xi_{t+1} \\
& =P P^{\prime}+\Psi_{1} P P^{\prime} \Psi_{1}^{\prime}+\cdots+\Psi_{S-1} P P^{\prime} \Psi_{S-1}^{\prime} \\
& =\sum_{j=1}^{k}\left(P_{j} P_{j}^{\prime}+\Psi_{1} P_{j} P_{j}^{\prime} \Psi_{1}^{\prime}+\cdots+\Psi_{S-1} P_{j} P_{j}^{\prime} \Psi_{S-1}^{\prime}\right)
\end{aligned}
$$

Which $P_{j}$ is the $j$ column matrix vector, the expression in brackets shows that the impact of $j$ orthogonal (or new) contribution to $s$ step prediction. Any endogenous variables forecast MSE could composited into the impact of the random variables contributions, and then calculated the relative importance of impact of each of variables. 


\section{GEWEKE INDICATORS}

Geweke (1982) supposed a direct measure of information feedback and interdependence among the securities markets. The method first assumes that in two countries stock markets return rate depends on another market rate of return over past, self market rate of return over past and noise. In this model, the two equations would be experienced seemingly unrelated Regression. Secondly, assumption same period and one-way simultaneity information feedback do not exist in two markets, that is parameters restrictions for first established equation and the use least squares to estimate the constraint equations. Finally, use estimated the variance-covariance residual of constraint equations and non-binding equation to structure a likelihood ratio. Statistics test the assumption, and determine information feedback and dependence relationship between the two markets.

\section{CONCLUSION}

There are four indicators when examining the linkage between the $\mathrm{A}+\mathrm{H}$ securities markets: the relevant parameters, co-integration relationships, Grange causality, and Geweke indicators. Related parameters are intuitive and simple. Co-integration can test long-run equilibrium relationships existing in a number of non-stationary time series. In its basis, we can establish the vector error correction model, in which we can also observe the short-term market movements, but cannot observe the details of long-run equilibrium relationship and the changes in characteristics and time-varying: The Granger causality test can directly determine the leading or lagging relationship in two markets, but the test prerequisite is a smooth time series, and non-stationary time series must be differenced before Grange causality test, but the information contained in variable differential suffered losses, and Granger causality test can only accept or reject the null hypothesis. LR statistic called Geweke-based indicators measure the A+H stock markets, which provides a measure of degree of direct linkage.

Research has also not yet found a linkage between $\mathrm{A}+\mathrm{H}$ stock markets perfect approaches, although less than the above method, but can complement each other. In short, the test theory of development is only used in practice. With expanding research, in the future there will also be more powerful theoretical tools for empirical analysis.

\section{REFERENCES}

B Alessandra and A. F. Carlo, (2005). "Explaining co-movements between stock markets: The case of US and Germany," Journal of International Money and Finance, vol. 24, Nov. 2005 pp. 1299-1316.

C. Kao and M. H. Chiang. (2000). "On the Estimation and Inference of a Co-integrated Regression in Panel Data," Advances in Econometrics, vol. 15, Feb. 2000, pp. 179-222.

C. Kao. (2001). "Spurious Regressions and Residual Based Tests for Co-integration in Panel Data," Journal of Econometrics, vol. 90, Jan. 2001, pp. 1-44.

G. Huang and F M. Song. (2005). "The Financial and Operating Performance of China's Newly Listed H-firms," Pacific Basin Financial Journal, vol. 13, Dec. 2005, pp. 53-83.

G. Meric and P. L. Ricardo, (2001). "Co-movements of US and Latin American equity markets before and after the 1987 crash,” International Review of Financial Analysis, vol. 78, Oct. 2001 pp. 219-235.

H. Q Zhang and M Yang, (2007). "Investment Opportunities in A - H Stock Market,” Economic Information, vol. 68, Jul. 2007, pp. 53-78.

P. B. Phillips and B. E. Hansen, (1990). "Statistical Inference in Individual Variables Regression with I(1) Process," Review of Economic Studies, vol. 57, Jun. 1990, pp. 99-125.

P. Pedroni (1999). “Critical Values for Co-integration Tests in Heterogeneous Panels with Multiple Regressors," Oxford Bulletin of Economics and Statistics, vol. 61, Mar. 1999, pp. 653-678.

S. Johansen, (1991). "Estimation and Hypothesis Testing of Co-integration Vectors in Gaussian Vector Autoregressive Models,” Econometrics, vol. 59, Jun. 1991, pp. 1551-1580.

S. Johansen, (1988). "Statistical Analysis of Co-integrating Vectors," Journal of Economic Dynamics and Control, vol. 94, Dec. 1988, pp. 231-254.

S. M. Strauss, (2000). "Exchange traded funds-the wave of the future?" Investment Lawyer, vol. 7, Apr. 2000, pp. $15-21$.

S. McCoskey and C. Kao, (1998). “A Residual Based Test of the Null of Co-integration in Panel Data,"Econometric Reviews, vol. 17, May. 1998, pp. 57-84. 